\title{
Cracking the Code of Distributed Leadership: New Insights from a Study of Leader Practitioners
}

\author{
Gail F. Latta \\ Xavier University
}

The landscape of distributed leadership has become littered with conceptual confusion. Spillane (2006) provided the foundation for a theory of distributed leadership by defining three conceptual forms: Collaborative, collective and coordinated. Despite its widespread intuitive appeal, traditional epistemological methods have hampered efforts to operationalize these distinct forms of leadership in practice. Cluster analysis provides an alternative method of analysis, revealing construct clarity by linking specific leadership and influence behaviors reported by middle-managers to each form of distributed leadership. Several forms of differentiated integration emerged from analysis, revealing more complexity than previously surmised and yielding a Model of Differentiated Leadership Integration.

\section{INTRODUCTION}

The landscape of distributed leadership has become littered with conceptual confusion (Bennett, Wise, Woods \& Harvey, 2003; Bolden, 2011; Mayrowetz, 2008). Despite its widespread intuitive appeal among practitioners, attempts to empirically operationalize core constructs have met with limited success (Bolden, Petrov \& Goslin, 2008; Harris, 2008; Hulpia, Devos \& Rosseel, 2009). Considering distributed leadership's distinctive pragmatic nature suggests the search for conceptual clarity has been hampered by the epistemological limitations of conventional research methods (Spillane, et al., 2008). Traditional content and factor analytic approaches to isolating discrete conceptual constructs may have limited utility for illuminating the forms of leadership distribution advanced by theorists, at least until greater clarity has been achieved regarding how these forms of leadership are practiced in the natural environment.

Although scholars have suggested distributed leadership exists in multiple forms (Gronn, 2002; McBeath, et. al., 2004; Leithwood, et al. 2006; Spillane, 2006), the assumption imposed by traditional empirical methods that these forms be constituted of mutually exclusive behaviors is neither theoretically necessary nor inherently true in practice. Rather, each form of distributed leadership may be characterized by a distinct set of behaviors and practices, some of which may be present in more than one form of leadership distribution. A reductionist approach that artificially constrains these differential forms to just those behaviors uniquely associated with each may account for the failure to capture the essence of distributed leadership using conventional positivist methodologies (Bryman, Stephens \& Campo, 1996). Validation of the theoretical constructs underlying distributed leadership requires alternative empirical methods capable of capturing distinct variations in leadership practice, without requiring all behaviors be discretely associated with just one form of leadership distribution. 
This study employs hierarchical cluster analysis as an alternative to conventional factor analysis to identify the leadership behaviors and influence tactics working professionals report employing in practicing distributed leadership (Capra, 2005; Everitt, Landau, Leese \& Stahl, 2011). Cluster analysis is the generic name for a set of statistical procedures well suited to revealing the underlying structure of qualitative or quantitative datasets, particularly when the researcher cannot state a priori how many categories may be present (Beckstead, 2002; Guest \& McLellan, 2003). Cluster analysis has been widely used across disciplines for developing typologies, generating or testing hypotheses, and validating the utility of conceptual frameworks by determining "whether classifications defined through other means are, in fact, present in a data set" (Beckstead, 2002, p. 308; Aldenderfer and Blashfield, 1984).

Alternative clustering algorithms applied to an overall similarity (or dissimilary) matrix govern the order of linkages among cases and determine the membership of both aggregate and terminal clusters (Jurowski \& Reich, 2000). Interpretation of the resulting dendrograms considers both the order and membership of cluster formation (Everitt, et al., 2011). Hierarchical cluster analysis is preferred over conventional factor analytic techniques when researchers wish to minimize loss of information contained in a set of observations due to complex variables that load on multiple factors. This makes the technique particularly appropriate for studying the potential overlap of behaviors associated with different forms of leadership distribution. While cluster analysis is a quantitative method, it includes a qualitative dimension related to the interpretation of emergent clusters, making it an ideal hybrid methodology for bridging the gap between theory and practice that has eluded scholars of distributed leadership employing conventional research methodologies.

\section{Distributed Leadership}

Distributed leadership (DL) is the inverse of heroic leadership, representing the influence of the collective on the individual, rather than "the singular influence of an individual" on the whole collective (Burke, 2010, p. 52). Distributed leadership has emerged as a distinct approach to collective leadership differing from shared (Pearce \& Sims, 2000), emergent (Seers, 1996), team (Hulpia, Devos \& van Keer, 2010), and co-leadership in the degree to which it describes processes that occur outside the context of a pre-defined group (Friedrich, et al. 2009). Bennett (2003) is recognized for capturing the three defining characteristics of distributed leadership as "an emergent property of a group or network of interacting individuals" exhibiting "openness of boundaries", where the "varieties of expertise are distributed across the many, not the few" (p. 7). Spillane (2006) provided the foundation for a theory of distributed leadership by identifying three conceptual forms of distribution: Collaborative, collective and coordinated. Taxonomies offered by other leadership scholars (Gronn, 2002; McBeath, et. al., 2004; Leithwood, et al., 2006) focus more on the genesis of distributed leadership, addressing how and why leadership may become distributed in certain contexts, rather than the specific behaviors and processes that constitute the essence of leadership distribution itself.

From its inception, distributed leadership has been defined as a set of overlapping forms that share many fundamental elements in common. Spillane's (2006) three conceptual forms of distribution (collaborative, collective and coordinated) emerged from the primacy he placed on considering the enacted nature of leadership, emphasizing processual elements of interaction among contributors operating from various vantage points within an organization. Gronn's (2002) taxonomy adopts an agentic perspective, delineating three forms of concerted action based upon the locus of genesis: spontaneous collaboration, intuitive working relations and institutionalized practices. Two necessary conditions common to all three are interdependence and coordination. In Gronn's framework, these concerted forms of distributed leadership represent a progression of "successive stages in a process of institutionalization" (Gronn, 2002, p.431), and each may manifest as either collectively or co-performed work, a distinction based upon the degree of temporal and physical proximity of the actors. From a processual perspective both collectively performed and co-performed distributed leadership may be enacted through formal or informal conjoint agency.

Other theorists have extended Gronn's taxonomy, further elaborating the degree of planful vs. spontaneous alignment (Leithwood, 2004), or contrasting the formal vs. pragmatic, strategic vs. cultural 
and opportunistic vs. incremental contexts giving rise to leadership distribution (MacBeath, et al., 2004). While a focus on the contextual nature of leadership is common to all these theorists, Spillane's (2006) perspective remains unique in its focus on capturing the nature of the interactions among individuals coperforming leadership functions regardless of the conditions giving rise to the distribution of these functions. For Spillane (2006), "interactions are paramount in efforts to understand the practice [of leadership] from a distributed perspective....aggregating their actions is insufficient” (p. 191).

\section{RESEARCH QUESTIONS}

The purpose of this study was to identify the relationship between Spillane's (2006) three forms of distributed leadership and the specific leadership and influence behaviors exhibited by practicing middle managers. Consideration was given to whether the behavioral associations predicted by distributed leadership scholars were mirrored in the pattern of interactions reported by practitioners working in environments conducive to the practice of distributed leadership. A taxonomy of leadership behaviors previously solicited from distributed leadership scholars provided a conceptual framework for interpreting survey data obtained from practitioners in middle management positions at participating organizations. A combination of cluster and factor analyses were used to triangulate data, yielding an alternative perspective on distributed leadership reflecting the experience of working professionals. The following research questions were addressed:

RQ1: What clusters of leadership behavior are associated with each of Spillane's (2006) three forms of distributed leadership: collaborative, collective, and coordinated?

Cluster analysis, was used to illuminate these conceptual and behavioral associations, in order to preserve behaviors exhibited in more than one form of leadership distribution (Capra, 2005). A secondary purpose of this study was to document the degree of correspondence between leadership experts' perspectives on distributed leadership and practitioners' reported behaviors:

RQ2: Are the behavioral associations predicted by distributed leadership scholars mirrored in the behavioral practices reported by individuals working in an unstructured task environment to accomplish a common goal?

This question was addressed by examining the intersection between predictions derived from expert ratings and cluster analysis of practitioners' behavioral data. A corollary question addressed is whether the behaviors associated with each form of leadership distribution are exclusive to that form, or if not, in what overlapping patterns these behaviors co-occur.

RQ3: Are the behaviors associated with each form of leadership distribution exclusive to that form, or if not, what overlapping patterns of association exist?

Comparative analysis of the behavioral associations resulting from the intersection of expert ratings and practitioner data determined the extent to which behavioral overlap exists among the forms of leadership distribution.

The differential use of influence tactics in association with the practice of different forms of leadership is well documented (Yukl, 2009). Thus, an examination of influence behaviors was included in the context of this study, both to further differentiate Spillane's forms of distributed leadership on the basis of established measures, and to verify the utility of the cluster analytic methodology for revealing structural patterns in similar survey data. Given the robust factor structure underlying the Influence Behavior Questionnaire (IBQ), this instrument provides a strong test of the methodological integrity of employing cluster analysis to reveal behavioral patterns in this study. 
RQ4: Which influence tactics are employed by individuals working in an unstructured task environment to accomplish a common goal?

Cluster analysis similar to that employed in addressing RQ1 were used to illuminate patterns of influence behaviors employed by practitioners working in a distributed leadership context. Evidence of convergence with the known factor structure of the IBQ was examined to validate the utility of cluster analysis for revealing behavioral associations in the dataset. The intersection of leadership and influence behaviors was explored to determine the differential association of Yukl's (2009) eleven influence tactics with Spillane's (2006) three forms of distributed leadership.

RQ5: Which influence tactics are associated with each of Spillane's (2006) three forms of distributed leadership (collective, collaborative, and coordinated)?

Traditional factor analytic methods were employed to explore the relationship between influence tactics and leadership behaviors employed by practitioners in a distributed context.

\section{METHODOLOGY}

\section{Survey Development}

This study focuses on the analysis of data collected using a survey instrument previously developed from focus groups conducted with middle managers to elicit the types of leadership behaviors they engaged in while working together as an unstructured work group to accomplish cross-institutional project (Zirkle, 2012). Focus groups were conducted at nine public and private organizations. Participants were asked to recall the project and discuss the nature of their interactions with other professional staff members throughout planning and execution, including how they came together, identified what needed to be done, the nature and frequency of their interactions, and how they keep moving forward to achieve desired outcomes. Participants were not told the study was about distributed leadership, although probing questions throughout sought to clarifying the types of leadership behaviors each member contributed and the degree to which leadership functions were either consolidated or distributed among multiple individuals at various points during the project. Distributed leadership was neither defined nor explicitly discussed as part of the focus group protocol so as not to bias responses.

Focus group transcripts were later coded using content analysis to identify the leadership behaviors reported. These behaviors were then categorized by a panel of experts (scholars) based on Spillane's (2006) conceptual definitions of distributed leadership: Collaborative Distribution - "the leadership practice involves leaders co-performing a leadership routine together in the same time and place. Collaborated distribution involves a reciprocal interdependency, in which the actions of different leaders involve input from one another co-performing a leadership routine"; Collective Distribution - "the leadership practice involves leaders who work separately but interdependently to co-perform a leadership routine.... situations in which two or more leaders are co-performing a routine but not in the same place or at the same time" ; Coordinated Distribution -"the leadership practice involves leadership co-performing a leadership routine in which they work separately or together on sequentially arranged leadership tasks that are necessary for the performance of the routine" (p. 61). This framework became the basis for the independent analysis of survey data and model creation that are the focus of this study. The focus groups and survey administration were conducted by a research associate to avoid biasing the analysis of survey data reported here.

\section{Survey Administration}

A 41-item leadership behavior survey, based on the taxonomy of leadership behaviors derived from the focus groups, was administered to a sample of middle managers at public and private organizations in Northeastern United States. Prior to completing the survey, these practitioners were asked to think of a cross-institutional project they worked on in the past 6 months involving an unstructured work group. 
Participants were asked to indicate on a 5-point Likert scale the frequency with which someone working on the project exhibited each behavior described by the survey instrument. Sample survey items included: "many opinions were sought before decisions were made"; "communication mostly occurred face-toface"; "most individuals worked independently"; "everyone was kept well informed"; "when meetings were held, everyone was expected to attend". These middle-managers also completed the 44-item IBQ (Yukl, 2004) using a similar response frame. Solicitation continued until 200 surveys were completed. Demographics of respondents suggest the sample was representative.

\section{RESULTS}

Results of data analysis are presented below in three sections. First separate cluster analyses of the leadership and influence behaviors reflected in responses to the practitioners' survey are presented. Second, results of the cluster analysis of practitioners' leadership behaviors are compared to the framework of distributed leadership obtained previously from leadership scholars. Finally, factor analysis of the practitioners' survey data is reported followed by correlational and regression analyses exploring the relationship between leadership and influence behaviors among middle-managers who responded to the survey. Following the presentation of these results, a Model of Distributed Leadership Integration consolidating findings from this study will be presented, along with a research agenda and implications for practitioners.

\section{Cluster Analysis}

Hierarchical cluster analysis provides a way of grouping survey items based upon the similarity of responses such that: 1) all items are retained, and 2) both the overlap and differentiation among items are revealed (Everitt, et.al., 2011). For purposes of this study, cluster analysis is the preferred method of analysis because it allows meaning to be extracted from survey ratings without any loss of information. The results reveal both the behaviors or influence tactics discretely associated with each form of distributed leadership (represented in the terminal clusters), as well as illuminating those behaviors or influence tactics that may be associated with more than one form of leadership distribution (represented in the aggregate clusters).

The purpose of this analysis was to determine the natural combinations of behaviors middle-managers reported engaging in while working in unstructured project-based environments conducive to distributed leadership. Using cluster analysis ensured that behaviors used with the same frequently were grouped together, forming a 'cluster' of leadership behaviors. Content analysis was then applied to each of these clusters to identify what the behaviors had in common. The clusters were assigned conceptual names denoting the common theme identified in each. Cluster analysis was applied separately to practitioners' survey responses to the leadership behavers and influence tactics surveys. Thus two cluster analyses were performed: one analysis clustered leadership behaviors, the other clustered influence tactics. The resulting dendrograms were analyzed for discrete, interpretable clusters and order of clustering, starting at the highest level. Conceptual labels were assigned to each discrete cluster that emerged from analysis.

\section{Leadership Behaviors Cluster Analysis}

The first cluster analysis performed on practitioners' survey data was based on their ratings of the frequency of leadership behaviors employed in their unstructured work groups. The resulting dendrogram is displayed in Figure 1. This dengrogram groups leadership behaviors by the frequency with which respondents reported employing them while completing a project with an unstructured work group. Both the order of grouping and the terminal clusters are significant: Behaviors grouped together higher in the hierarchy were employed with the same degree of frequency. The terminal clusters represent constellations of behaviors that were frequently use together. Interpretation of the dendrogrm focused on content analysis of the terminal clusters, as well as the order in which these clusters were joined into meaningful aggregate clusters. Starting at the top and progressing to the lowest level of analysis, nine 
terminal clusters were extracted from the Practitioners' Leadership Behaviors dendrogram. Survey item membership for each of these clusters is presented in Figure 2.

Interpretation of these emergent clusters proceeded with an examination of the specific leadership behaviors from the practitioners' survey grouped together in each cluster, with a focus on discerning the shared meaning contained. Based on this analysis, the following clusters were identified and labeled as detailed in Table 1. Using content analysis, conceptual definitions were assigned to each emergent cluster as follows: Cluster A reflects interdependence among all participants or contributors to a project. Cluster $\mathrm{B}$ concerns the conduct of structured meetings involving all participants. This contrasts with Cluster $\mathrm{C}$ which reflects reliance on email or telephone communication for decision making, i.e. virtual meetings. Cluster D contains items governing work carried out separately and sequentially as serial integration, while Cluster E reflects greater integration of all participants throughout as holistic integration. Items in Cluster F concern efforts to ensure a high level of involvement by all contributors to a project. Cluster $\mathrm{G}$ concerns the division of labor to be spread out across multiple contributors working either simultaneously or sequentially.

FIGURE 1

PRACTITIONERS' LEADERSHIP BEHAVIORS CLUSTER ANALYSIS DENDROGRAM

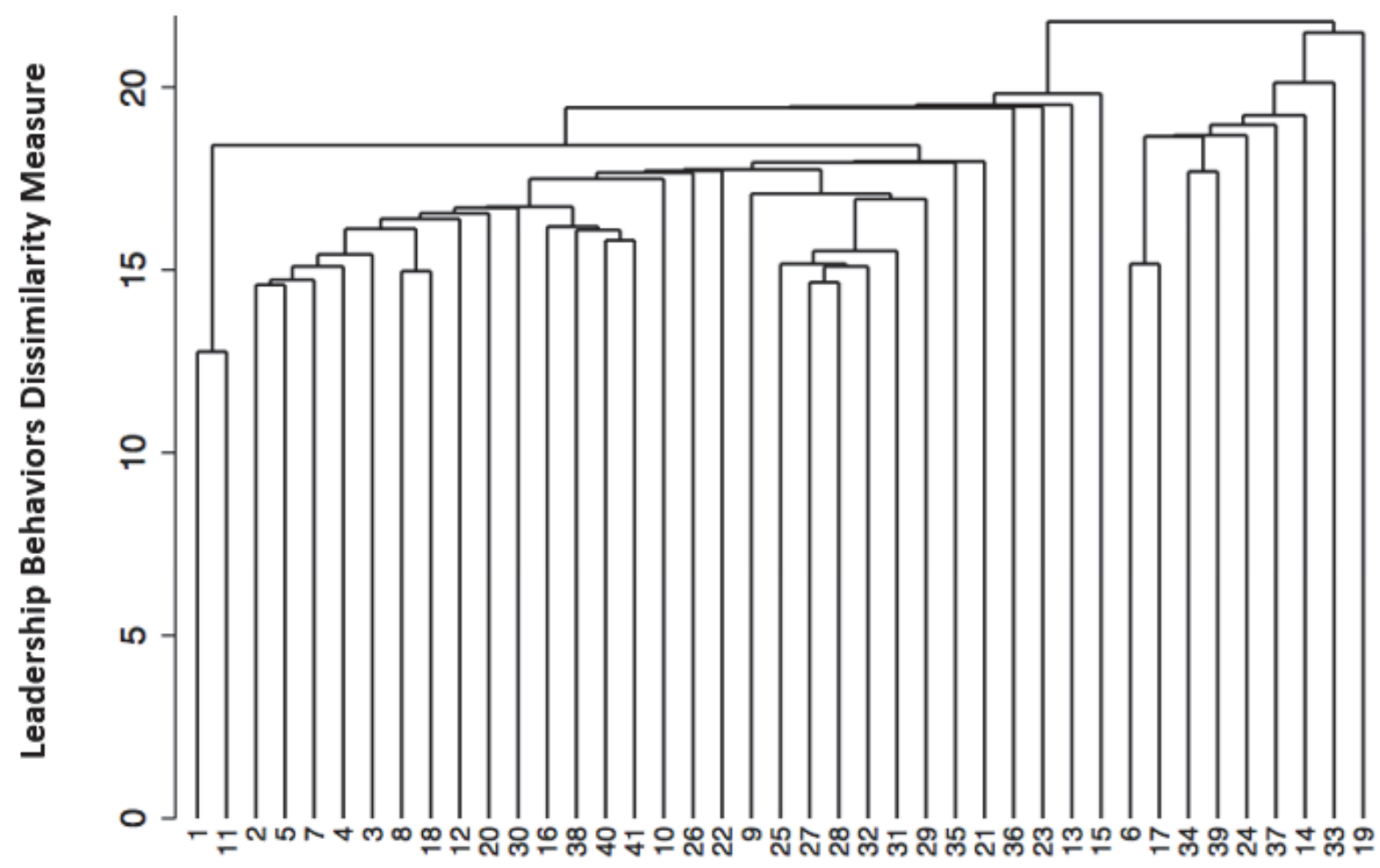


FIGURE 2

ORDER OF CLUSTER FORMATION FROM PRACTITIONERS'

LEADERSHIP BEHAVIORS SURVEY

\begin{tabular}{|c|c|c|c|c|c|c|c|c|c|}
\hline \multicolumn{8}{|c|}{$\begin{array}{l}1,2,3,4,5,7,8,9,10,11,12,13,15,16,18,20,21,22,23,25,26,27,28,29,30, \\
31,32,35,36,38,40,41\end{array}$} & \multicolumn{2}{|c|}{$\begin{array}{l}6,14,17,19.24, \\
33,34,37,39\end{array}$} \\
\hline \multicolumn{7}{|c|}{$\begin{array}{l}1,2,3,4,5,7,8,9,10,11,12,16,18,20,21,22,25,26,27,28,29,30, \\
\text { 31. 32. 35. 38. } 40.41\end{array}$} & \multirow{4}{*}{$\begin{array}{l}13^{*}, \\
15^{*}, \\
23^{*}, \\
36^{*}\end{array}$} & \multirow{4}{*}{$\begin{array}{l}6,17, \\
24,34, \\
37,39\end{array}$} & \multirow{4}{*}{$\begin{array}{l}14^{*}, \\
19^{*} \\
33^{*}\end{array}$} \\
\hline \multirow[t]{3}{*}{1,11} & \multicolumn{4}{|c|}{$\begin{array}{l}2,3,4,5,7,8,12,16,18,20,30,38 \\
40,41\end{array}$} & \multirow{3}{*}{$\begin{array}{l}10,21^{*}, \\
22,26, \\
35^{*}\end{array}$} & \multirow{3}{*}{$\begin{array}{l}9,25, \\
27,28 \\
29,31 \\
32\end{array}$} & & & \\
\hline & \multicolumn{3}{|c|}{$\begin{array}{l}2,3,4,5,7,8,12,18,20,30, \\
38\end{array}$} & \multirow[t]{2}{*}{$\begin{array}{l}16,38 \\
40,41\end{array}$} & & & & & \\
\hline & $\begin{array}{l}2,3,4 \\
5,7\end{array}$ & 8,18 & $\begin{array}{l}12,20, \\
30\end{array}$ & & & & & & \\
\hline $\bar{A}$ & B & $\bar{C}$ & D & $\mathbf{E}$ & $\mathbf{F}$ & $\mathbf{G}$ & & H & \\
\hline
\end{tabular}

*These items failed to form an interpretable terminal cluster

TABLE 1

TERMINAL CLUSTERS EXTRACTED FROM PRACTITIONERS' LEADERSHIP BEHAVIORS SURVEY

\begin{tabular}{ccc}
\hline Cluster & Label & Survey Items* \\
\hline Cluster A & Interdependence & 1,11 \\
Cluster B & Structured meetings & $2,34,5,7$ \\
Cluster C & Virtual meetings & 8,18 \\
Cluster D & Serial Integration & $12,20,30$ \\
Cluster E & Holistic Integration & $16,38,40,41$ \\
Cluster F & Involvement & $10,21,22,26,35$ \\
Cluster G & Division of Labor & $9,25,27,28,29,31.32$ \\
Cluster H & Group supervision & $6,17,24,34,37,39$ \\
\hline
\end{tabular}

*Item numbers from Practitioners' Leadership Behaviors Survey

Higher up in the hierarchy of the cluster analysis (above the terminal clusters), aggregate clusters were also forms and assigned conceptual labels. Clusters B and C combine before joining with other clusters, and together reflect alternative forms of logistical integration. Clusters B, C, D and E create an aggregate cluster, reflecting alternative forms of integration among project participants or contributors, before joining with other clusters. In the overall factor structure, Clusters A (interdependence) and $\mathrm{F}$ (involvement) join simultaneously with Clusters $\mathrm{G}$ (division of labor) creating the combined Cluster $\mathrm{BCDE}$ (forms of integration). This was interpreted as indicating that interdependence and involvement are essential elements of all three forms of leadership distribution, rather than being a distinguishing feature of any particular form of distributed leadership. Cluster $\mathrm{H}$ contains items describing supervised group work and was labeled group supervision, while Cluster I describes supervised work conducted independently, individual supervision. In the overall factor structure, Clusters H (group supervision) and I 
(individual supervision) merge to create an aggregate cluster separate from the other leadership behaviors, together representing hierarchical leadership (see Table 1).

\section{Influence Tactics Cluster Analysis}

Hierarchical cluster analysis was also performed on the IBQ portion of the practitioners' survey. These data reflect how frequently participants reported employing various influence behaviors in completing an unstructured project. The resulting dendrogram presented in Figure 3 was analyzed for interpretable clusters and order of aggregation. Ten discrete terminal clusters were identified, each corresponding to one of Yukl's (2009) influence tactics; cluster membership and interpretation are presented in Figure 4 and Table 2, respectively. Only pressure and personal appeals were aggregated in the cluster dendrogram, rather than emerging as separate terminal clusters. Three clusters, AA, FF, and JJ, correspond exactly to the rational persuasion, exchange and legitimizing tactics, respectively. Four clusters, $\mathrm{CC}, \mathrm{EE}, \mathrm{HH}$ and II, contained all items corresponding to the consultation, ingratiation, coalition, and apprising tactics, respectively, plus one additional unrelated item each. Cluster DD contained three of four items corresponding to collaboration, and cluster BB contained two of four items corresponding to inspirational appeals. The final terminal cluster GG, contained all four items corresponding to personal appeals and three of four pressure tactic items. In the final analysis, all terminal clusters resulting from the influence behaviors dendrogram were interpretable in light of Yukl's influence tactics taxonomy (Yukl, Seifert \& Chevez, 2008).

In addition to the meaning attached to the terminal clusters, the order of clustering within the dendrogram conveys additional meaning about the relationships among the terminal clusters. The following cluster order was documented: Rational persuasion and inspirational appeals clustered together before joining at the next level with consultation. Collaboration and ingratiation then joined this cluster, creating an final aggregate cluster consisting almost entirely of soft appeals (Hughes, Ginnett, \& Curphy, 1993). On the other side of the dendrogram, exchange behaviors joined the terminal cluster containing elements of both pressure and personal appeals, before subsequently joining with coalition. This aggregate cluster joined successively to the apprising and legitimizing clusters at each of the next levels, creating a final aggregate cluster consisting almost entirely of hard appeals (Hughes et al., 1993) (see Table 2). 
FIGURE 3

PRACTITIONERS' INFLUENCE BEHAVIORS CLUSTER ANALYSIS DENDROGRAM

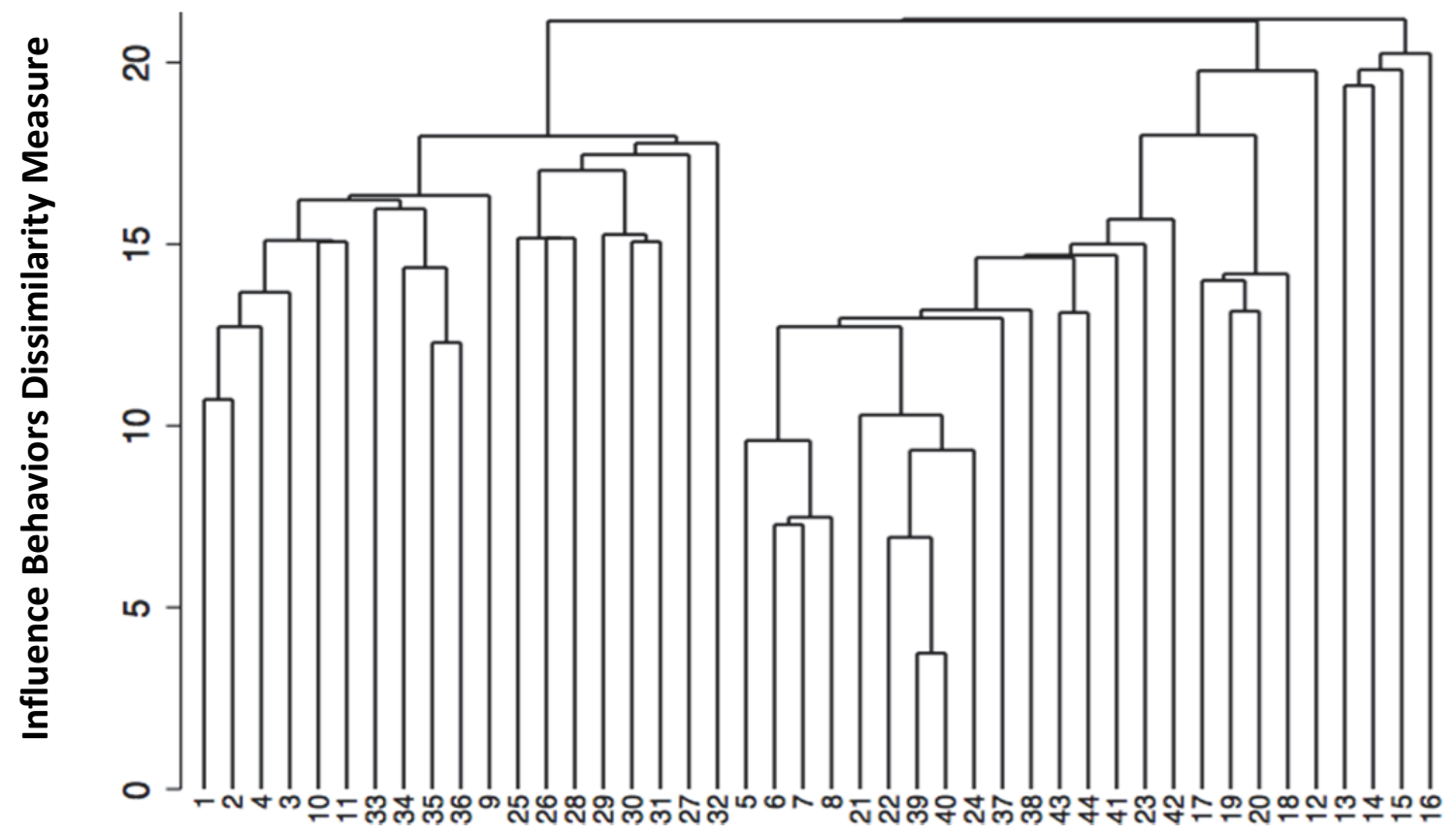

FIGURE 4

ORDER OF CLUSTER FORMATION FROM PRACTITIONERS' INFLUENCE BEHAVIORS SURVEY

\begin{tabular}{|c|c|c|c|c|c|c|c|c|c|}
\hline $\begin{array}{l}1,2,3,4, \\
33,34,35\end{array}$ & $\begin{array}{l}10,11 \\
36\end{array}$ & $26,27,2$ & $8,29,3$ & 1,32 & \begin{tabular}{|l}
$5,6,7,8$ \\
$24,37,38$
\end{tabular} & $\begin{array}{l}12,17, \\
39,40\end{array}$ & $\begin{array}{l}19,20, \\
42,43,\end{array}$ & , 22, 23, & $\begin{array}{l}13,14, \\
15,16\end{array}$ \\
\hline $\begin{array}{l}1,2,3,4, \\
36\end{array}$ & $9,10,11$ & $3,34,35$ & $\begin{array}{l}25,26, \\
30,31,\end{array}$ & 28,29 & $\begin{array}{l}5,6,7,8 \\
38,39,40\end{array}$ & $\begin{array}{l}21,22,2 \\
41,42,\end{array}$ & $\begin{array}{l}24,37 \\
, 44\end{array}$ & $\begin{array}{l}12,17, \\
18,19,\end{array}$ & \\
\hline $1,2,3,4$, & 10,11 & $\begin{array}{l}9,33,34 \\
35,36\end{array}$ & $\begin{array}{l}25,26 \\
28\end{array}$ & $\begin{array}{l}27,29 \\
30,31\end{array}$ & $\begin{array}{l}5,6,7,8 \\
24,37,38\end{array}$ & $\begin{array}{l}21,22 \\
39,40\end{array}$ & $\begin{array}{l}23,41 \\
42,43,\end{array}$ & & \\
\hline $1,2,4,3$ & 10,11 & & & & $5,6,7,8$ & $\begin{array}{l}21,22, \\
24,37 \\
38,39 \\
40\end{array}$ & & & \\
\hline $\mathbf{A A}$ & BB & $\mathrm{CC}$ & DD & $\mathbf{E E}$ & FF & GG & HH & II & JJ \\
\hline
\end{tabular}


TABLE 2

TERMINAL CLUSTERS EXTRACTED FROM PRACTITIONERS' INFLUENCE BEHAVIORS SURVEY

\begin{tabular}{ccc}
\hline Cluster & Label & Survey Items* \\
\hline Cluster AA & Rational persuasion & $1,2,3,4$ \\
Cluster BB & Inspirational Appeals & 10,11 \\
Cluster CC & Consultation & $9,33,34,35,36$ \\
Cluster DD & Collaboration & $25,26,28$ \\
Cluster EE & Ingratiation & $27,29,30,31,32$ \\
Cluster FF & Exchange & $5,6,7,8$ \\
Cluster GG & Pressure/Personal & $21,22,24 / 37,38,39$, \\
Cluster HH & Appeals & 40 \\
Cluster II & Coalition & $23,41,42,43,44$ \\
Cluster JJ & Apprising & $12,17,18,19,20$ \\
& Legitimizing & $13,14,15,16$ \\
\hline
\end{tabular}

*Item numbers from Yukl's (2003) Influence Behavior Questionnaire (Agent G-44)

\section{Comparing Practitioners' Cluster Analyses with Scholars' Conceptual Framework}

Interpretation of the emergent clusters of leadership behaviors derived from cluster analysis continued by examining how each cluster related to Spillane's (2006) conceptual forms of leadership distribution. This comparison was facilitated by the framework linking behaviors on the survey instrument to Spillane's conceptual definitions derived previously through analysis of leadership scholars' expert opinion. This comparative analysis detailing the degree of correspondence between leadership behaviors associated with distributed leadership by study participants and leadership scholars' is presented in Figure 5. Only one of the emergent clusters, serial integration, discretely associated with a single form of leadership distribution, coordinated. A far more intricate pattern of associations was evident among the remaining clusters: 
FIGURE 5

MODEL OF DISTRIBUTED LEADERSHIP INTEGRATION LINKING RESULTS OF CLUSTER ANALYSIS TO SPILLANE'S FORMS OF LEADERSHIP DISTRIBUTION

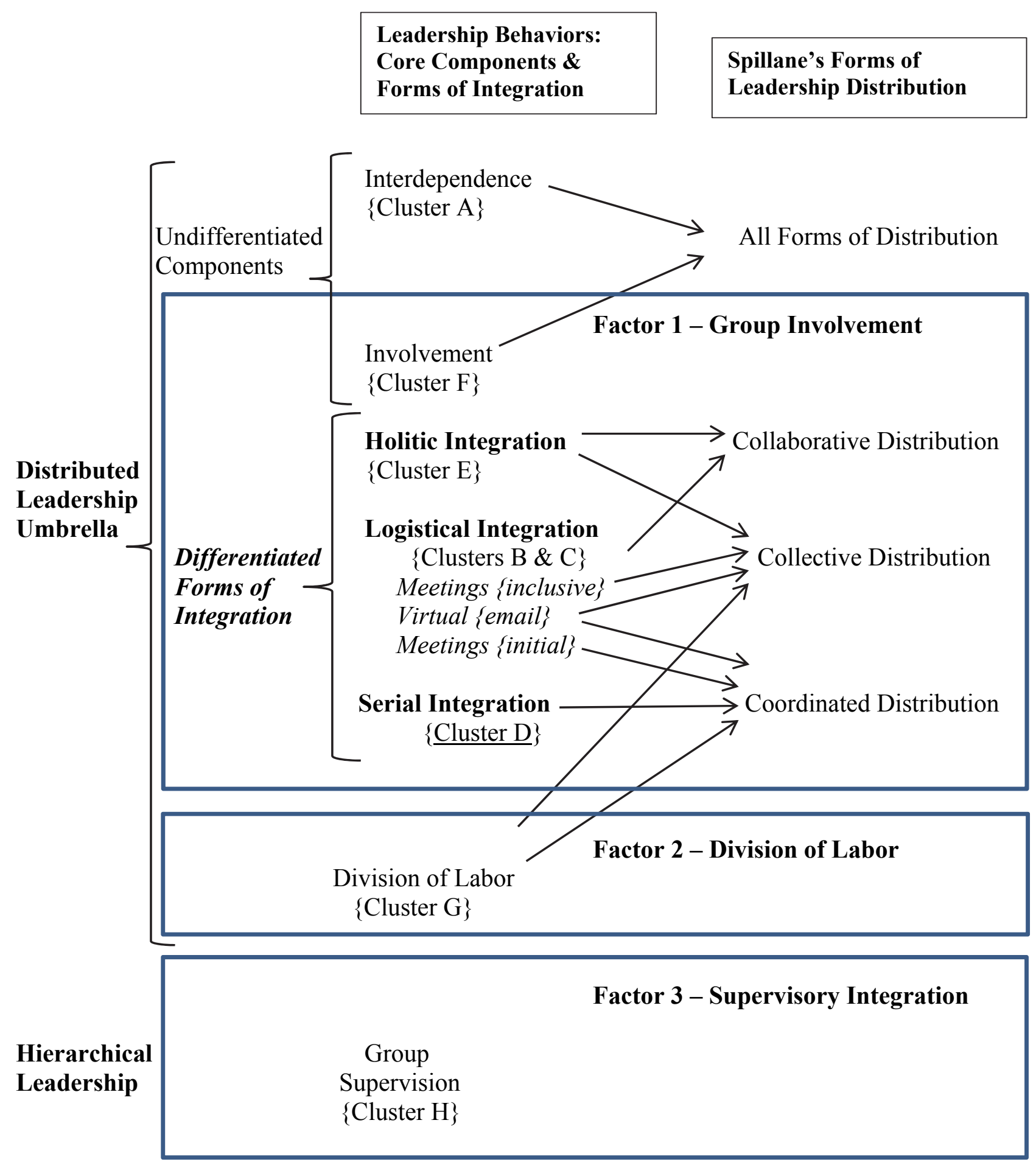


Clusters A and F, representing interdependence and involvement respectively, were associated with all of Spillane's (2006) conceptual definitions, suggesting that the overall engagement of participants is a core component of all forms of distributed leadership. Both holistic integration (Cluster E) was associated with both collaborative and collective distribution, while division of labor (Cluster $\mathrm{G}$ ) was associated with both coordinated and collective distribution. Components of the aggregate logistical integration cluster associated with all forms of distribution, although the types of logistical tactics differed. Collaborative and collective distribution were associated with structured meetings of the whole involving brainstorming (inclusive meetings), while coordinated distribution was associated with structured meetings involving an agenda only at the start of a project, after which meetings are rare (initial meetings). Virtual meetings were associated with both collective and coordinated forms of distribution, but not with collaborative.

Based on this analysis, separate components of the aggregate cluster forms of integration were found to be differentially associated with each of the three forms of leadership distribution; this cluster containing holistic, logistical and serial integration was renamed, differentiated forms of integration. The two clusters found to be associated with all forms of distribution, interdependence and involvement, were labeled undifferentiated components; these clusters linked simultaneously with the differentiated forms of integration and division of labor clusters. Together, these three components were found to contain the distributed leadership umbrella. The remaining leadership behaviors included on the leadership behavior survey clustered separately from the items associated with distributed leadership by the experts. These items describe various supervisory functions. Viewed through the lens of the experts' associations, this cluster consists mostly of items not associated with any of Spillane's (2006) conceptual forms of distribution. Thus from a behavioral perspective, supervisory forms of leadership was found to lie outside the distributed leadership umbrella.

The distributed leadership umbrella that emerged from this analysis is inclusive of, but more complex than, the three discrete forms of distribution conceptualized by Spillane (2006). From a cluster analysis perspective, distributed leadership looks empirically less like three discrete forms, and more like three hybrid constructs representing complex patterns of differentiated and undifferentiated behaviors. While the core components interdependence and involvement are characteristic of all forms of leadership distribution, collaborative leadership involves both holistic integration and structured meetings; coordinated distribution also involves holistic integration, but is characterized by more virtual meetings and a division of labor; coordinated distribution similarly involves both a division of labor and serial integration, but lacks the component of group integration characteristic of other forms of distribution, and is logistically distinct in relying to a greater extent on virtual and initial meetings. The fact that division of labor clusters separately from other differentiated and undifferentiated elements supports the conceptual distinction of this component of distributed leadership.

\section{Factor Analysis}

Exploratory factor analysis subsequently performed on both sets of practitioners' data supported a 3factor model for leadership behaviors and a 2-factor model for influence tactics. Criteria for item retention included Eigen values scree test, a factor loading cut off of .30 and factor interpretability; complex variables that loaded on more than one dimension were dropped.

\section{Leadership Factors}

The three leadership behavior factors contained 14, 8 and 5 items, respectively, with 14 items excluded; coefficient alphas for each of the factors were $.86, .81$, and .66 . While the factor loadings did not exactly match results of the cluster analysis, there was substantial correspondence. Examining the content of each factor loading revealed these three factors corresponded to three leadership behavior clusters identified through cluster analysis: group involvement, supervisory integration, and division of labor. The smaller two factors, accounting for $14 \%$ and $5 \%$ of the shared item variance, corresponded to the terminal clusters reflecting supervisory integration and division of labor. In corroborating results of the cluster analysis, these findings suggest that for these two components of leadership, factor analysis served an equally sufficient method of analysis. The third factor, accounting for an additional $14 \%$ of the 
shared item variance, did not correspond to a terminal cluster, but to the aggregate cluster group involvement. This aggregate cluster was constituted of all three differentiated forms of integration (holistic, logistical and serial) combined, plus involvement. Disaggregating this factor into terminal clusters revealed that only one of the components loading on this factor (involvement) was associated with all three forms of distribution; the other three were each differentially associated with two forms of distribution, exclusive of the third (see Figure 5).

The results of this analysis provides strong evidence to suggest that in practice, rather than being constituted of three distinct forms as proposed conceptually by Spillane, distributed leadership actually consists of overlapping leadership behaviors that have much more in common than previously postulated by theorists. This study reveals that by eliminating complex variables and forcing items into discrete factors, previous studies of distributed leadership artificially obscured the complex overlapping patterns of behavioral associations revealed through cluster analysis. On the other hand, factor analysis in this study did reveal one item (group supervision) that negatively loaded on the aggregate distributed leadership factor but that clustered with supervisory integration; this association was not evident from cluster analysis alone.

\section{Influence Factors}

The two influence behavior factors identified contained 21 and 17 items each, with 5 items excluded; coefficient alphas for each of the factors were .92 and .88. While the factor loadings did not exactly match results of the cluster analysis, there was substantial correspondence. The two factors, accounting for $28 \%$ and $13 \%$ of the shared item variance, corresponded to the aggregate clusters representing soft and hard appeals (Hughes et al., 1993), respectively. Once again, the complex internal structure of these factors was revealed only through cluster analysis. A test of the 11 factor structure advanced by Yukl, et al. (2008), did not yield a good fit, as indicated by the significant chi-square, $X^{2}(847, \mathrm{~N}=261)=1404.194 \mathrm{p}$ $=0.00, \mathrm{CFI}=.89,(\mathrm{RMSEA})=.059(90 \%$ confidence interval $=.053-.064)$.

\section{Correlation and Regression Analyses}

Finally, the relationship between leadership and influence behaviors was explored using correlation analysis (see Table 3).

TABLE 3

CORRELATION MATRIX: LEADERSHIP AND INFLUENCE BEHAVIOR FACTORS

\begin{tabular}{|c|c|c|c|c|c|}
\hline & $\begin{array}{c}\text { Group } \\
\text { Involvement }^{1} \\
\text { (integrated) }\end{array}$ & $\begin{array}{l}\text { Division of } \\
\text { Labor }^{2} \\
\text { (independent) }\end{array}$ & $\begin{array}{l}\text { Supervisory } \\
\text { Integration }^{3} \\
\text { (hierarchical) }\end{array}$ & Hard Appeals & Soft Appeals \\
\hline Group & 1.00 & & & & \\
\hline \multicolumn{6}{|l|}{ Involvement } \\
\hline Division of Labor & $0.47 * * *$ & 1.00 & & & \\
\hline Supervisory & -0.12 & 0.10 & 1.00 & & \\
\hline \multicolumn{6}{|l|}{ Integration } \\
\hline Hard Appeals & $0.35 * * *$ & $0.41 * * *$ & $0.33 * * *$ & 1.00 & \\
\hline Soft Appeals & $0.31 * * *$ & $0.67 * * *$ & 0.07 & $0.27 * * *$ & 1.00 \\
\hline
\end{tabular}




\section{Correlation Analysis}

The correlation matrix presented in Table 3 reveals significant correlations between the aggregate distributed leadership factors group involvement and division of labor $(\mathrm{r}=.47 ; p<0.001)$; neither was significantly correlated with supervisory integration. The two influence factors were also significantly correlated $(\mathrm{r}=.27 ; p<0.001)$. The use of soft appeals was significantly correlated with both group involvement $(\mathrm{r}=.31 ; p<0.001)$ and division of labor $(\mathrm{r}=.67 ; p<0.001)$, while the use of hard appeals was significantly correlated with all three leadership factors: group involvement $(\mathrm{r}=.35 ; \mathrm{p}<0.001)$, division of labor $(\mathrm{r}=.41 ; p<0.001)$, and supervisory integration $(\mathrm{r}=.33 ; p<0.001)$.

\section{Regression Analysis}

Three independent regression equations were calculated to determine the amount of leadership variance accounted for by each of the influence factors identified in this study (see Table 4). For each regression equation, the independent variables were the practitioners' use of hard and soft appeals, while the dependent variable in each equation was one of the three leadership components that emerged from combining the cluster and factor analyses: group involvement, division of labor and supervisory integration. The overall regression equation reached significance for all three forms of leadership: group involvement, $F(2,190)=19.91 ; \mathrm{p}<.001 ;$ division of labor, $F(2,190)=96.09 ; \mathrm{p}<.001 ;$ and supervisory integration, $F(2,190)=11.27 ; \mathrm{p}<.001$. Hard and soft appeals accounted for a significant portion of the variance in both the aggregate distributed leadership factors, group involvement $(16 \%)$ and serial integration $(50 \%)$ forms of leadership; only hard appeals accounted for a significant amount of the variance in the supervisory integration (10\%) leadership factor. Overall, hard appeals were employed across all forms of leadership and accounted for roughly the same amount of variance in each, while soft appeals were systematically employed in all forms of leadership except supervisory integration, and accounted for a much greater portion of the variance in distributed leadership than in either serial or supervisory forms of integration.

TABLE 4 REGRESSION ANALYSIS OF LEADERSHIP AND INFLUENCE BEHAVIORS

\begin{tabular}{|c|c|c|c|}
\hline \multirow[b]{2}{*}{ Independent Variables } & \multicolumn{3}{|c|}{ Dependent Variables } \\
\hline & $\begin{array}{c}\text { Group } \\
\text { Involvement }^{1} \\
\text { (integrated) }\end{array}$ & $\begin{array}{c}\text { Division } \\
\text { of Labor }{ }^{2} \\
\text { (independent) }\end{array}$ & $\begin{array}{l}\text { Supervisory } \\
\text { Integration }^{3} \\
\text { (hierarchical) }\end{array}$ \\
\hline Hard Appeals & $\begin{array}{l}0.28 * * * \\
(0.08)\end{array}$ & $\begin{array}{l}0.25 * * * \\
(0.06)\end{array}$ & $\begin{array}{l}0.33 * * * \\
(0.04)\end{array}$ \\
\hline Soft Appeals & $\begin{array}{l}0.24^{* *} \\
(0.13)\end{array}$ & $\begin{array}{l}.60^{* * * *} \\
(0.10)\end{array}$ & $\begin{array}{l}-0.02 \\
(0.07)\end{array}$ \\
\hline $\begin{array}{l}\mathrm{F}(\mathrm{df}=2,190) \\
\mathrm{R}^{2}\end{array}$ & $\begin{array}{l}19.91 * * * \\
0.16\end{array}$ & $\begin{array}{l}96.09 * * * \\
0.50 \\
\end{array}$ & $\begin{array}{l}11.27 * * * \\
0.10\end{array}$ \\
\hline
\end{tabular}




\section{CONCLUSIONS}

Results of this study of working practitioners suggest distributed leadership is far more complex than previously conceptualized by scholars. Evidence using cluster analysis reveals that rather than consisting of separate, discrete forms, distributed leadership is actually constituted of multiple overlapping forms. Three forms of leadership distribution were identified in the terminal clusters derived from that analysis of practitioners' survey data in this study: holistic, logistical and serial leadership. These forms of leadership distribution are different than those previously proposed by theorists, although there were some commonalities noted. But what appears to be more important is that the forms of distributed leadership identified in this study share more in common than scholars previously thought, but are nevertheless clearly distinct from traditional hierarchical leadership approaches, as corroborated by the evidence presented here.

\section{Conceptualizing Distributed Leadership}

Compared with experts' conceptual associations of leadership behaviors obtained previously, which substantially aligned with Spillane's (2006) conceptual definitions, survey responses from practitioners in this study yielded a far more intricate framework of behavioral integration. Importantly, these findings were based on the ways in which leadership professionals actually reported interacting in unstructured task environments. These findings support the conclusion that in the way it is practice, distributed leadership is not as discrete or exclusive as Spillane's (2006) conceptual definitions purport.

In practice, the three conceptual forms of distributed leadership defined by Spillane (2006) disaggregate on the basis of cluster analysis into three forms of integration that are differentially associated with the three forms of leadership distribution, while a fifth form integration representing hierarchical (supervisory) leadership was found to lie empirically outside the distributed leadership umbrella. Two additional behavioral clusters, identified as interdependence and involvement, were found to be associated with all forms of distributed leadership, while a final cluster representing division of labor was associated with two forms. None of the core components or differentiated forms of integration were exclusively associated with a single form of distributed leadership, yet Spillane's (2006) distinct forms of distribution were clearly distinguishable within the pattern of associations revealed through cluster analysis. These results suggest that involvement and interdependence are essential core constructs differentiating all forms of distributed leadership from traditional hierarchical leader-follower relationship. What distinguishes these forms of leadership distribution appears to be the manner of behavioral integration and division of labor that characterizes each.

Insights were also gained in this study into the relationship between leadership behaviors of middlemanagers and their use of influence tactics in unstructured working groups. Results of the correlation and regression analyses revealed these leaders used both hard and soft influence tactics with all forms of leadership where a division of labor, group involvement, or supervisory integration were involved. However, soft appeals were only practiced when the nature of leadership involved a division of labor and group involvement; soft appeals were not employed to promote supervisory integration. Thus it is not the absence of hard appeals that characterizes distributed forms of leadership, but the presence of soft appeals not typically associated with hierarchical leadership.

\section{Emergent Model of Distributed Leadership Integration}

Results of this study suggest the distributed leadership umbrella encompasses both differentiated and undifferentiated elements. The undifferentiated elements of distributed leadership are: a) the interdependence and involvement of all members of a work group. These elements were found to be common to all types distributed leadership. In addition, this study identified three Differentiated Forms of Integration that exist under the umbrella of distributed leadership: Holistic, logistical and serial integration. Integration is a new construct not previously considered in conceptualizing distributed leadership and distinguishing among its various forms. 
The Model of Distributed Leadership Integration that emerged from this study highlights the many different types of behavioral integration that characterize various forms of leadership distribution: Holistic integration was characterized by behaviors that ensured input, opinions and work completed individually were shared openly with all members of the work group to inform problem solving, decision making and ensure everyone maintained a holistic sense of the project throughout implementation. Logistical integration captured the mechanisms by which, whether working alone or together, members of the work group coordinated their activities and strategically sought the perspectives of others as needed to carry out their tasks. Finally, serial integration refers to the procedures that ensured work was carried out in an orderly, coordinated and sequential manner coordinated by a unifying agenda and facilitated by personal communication.

Based on the results of this study, what distinguishes each of Spillane's (2016) conceptual forms of distributed leadership are the types of differentiated integration required in practice (see Figure 5). Collaborative distribution requires both holistic and logistical integration. Collective distribution requires both holistic and serial integration. Coordinated distribution requires both logistical and serial integration. In addition, both collective and coordinated distribution require an element of division of labor, while collaborative distribution does not. Significantly, the only type of integration not found to be a component of any form of distributed leadership was supervisory integration. This form of hierarchical leadership was found to be outside the umbrella of distributed leadership. Thus while each of Spillane's identified forms of leadership distribution are conceptually distinct, results of this study provide strong evidence that in practice, the behaviors underlying these leadership forms are exercised in particular combinations of both differentiated and undifferentiated behaviors. All forms of distributed leadership were found to require both interdependence and involvement, as well as some combination of holistic, logistical or serial integration. But there was not a singular, one-to-one correspondence between these various types of differentiated integration and Spillane's (2006) conceptually distinct forms of distributed leadership. Together, these data support the conclusion that in practice, distributed leadership is a much more complex, dynamic, unscripted form of leadership that requires a diverse set of behavioral skills to execute successfully.

\section{Paradigm Shift in the Study of Distributed Leadership}

The results of this study, utilizing less traditional methods to analyze the behavior of middlemanagers in unstructured work environments, produced findings that suggest a paradigm shift is needed in the study of distributed leadership. More commonality than distinction was found among the forms of distributed leadership documented than have been conceptually defined by scholars previously (Gronn, 2002). This suggests the search for discrete forms of leadership distribution should be replaced with a more nuanced approach to complexity analysis using alternative research methods (Osborn \& Hunt, 2007; Uhl-Bien \& Marion, 2009).

In addition, Spillane's (2006) focus on interpersonal interaction as the defining dimension distinguishing distributed leadership may need to be replaced with consideration of the nature of integration within distributed work groups. Several forms of integration emerged as the defining dimension of both differentiated and hierarchical leadership in this study. Differentiating among work groups based on these dimensions may hold promise for advancing the study of distributed leadership beyond concern over the behavior of individuals, to considering the fitness of the entire collective. Defining a form of leadership based on individual interactions may have less relevance for understanding the nature of distributed leadership (and other forms of collective leadership), than finding ways to characterize the level of overall integration of leaders and followers engaged in carrying out the work of an organization.

Understanding how members of unstructured work groups are integrated, as well as the factors that promote and sustain optimal levels of integration relative to the nature of the work to be completed, represents a promising new research agenda for scholars of distributed leadership. Other lines of future research suggested by the results of this study include assessing the differential success and effectiveness of the various forms of differentiated integration identified, as reflected in the Model of Distributed 
Leadership Integration. Researchers should seek to determine the optimal level of each form of integration, depending upon the form of leadership distribution being practiced. What are the essential skill sets associated with each of these forms of integration that leaders need to master in order to practice effective distributed leadership? Closer examination of the differential use of hard and soft influence tactics may further clarify what appears to be a tipping point in distinguishing distributed from hierarchical forms of leadership.

\section{Implications for Leadership Practice}

Even before being confirmed and extended through future research, the results of this study have numerous implications for practitioners, particularly middle-managers expected to provide leadership in unstructured environments. First, the practice of distributed leadership appears to be a complex, multifaceted skill that invites creativity and relies on intuition, ingenuity and a commitment to promoting integration of all individuals contributing to the collective effort. Given that all forms of distributed leadership were shown to require both interdependence and involvement of group members, leaders should remain vigilant in monitoring these dynamics throughout project completion.

In addition, three forms of integration (holistic, logistical and serial) appear to be important for enacting different forms of distributed leadership; the Model of Distributed Leadership Integration presented in Figure 5 provides a roadmap for leaders attempting to strike the optimal levels of each. At the same time, it appears that supervisory integration should be avoided. It may also be important to bear in mind that a formal division of labor is not required for all forms of leadership distribution.

Results of this study also point to the importance of relying upon soft influence tactics to garner the contributions of group members, together with a more attenuated, selective use of more traditional hard appeals. These guidelines provide an abundance of insight for leaders striving to succeed in organizations that advocate the distribution of leadership for achieving organizational objectives.

\section{REFERENCES}

Aldenderfer, M. S., \& Blashfield, R.K. (1984). Cluster analysis. (Quantitative Applications in the Social Sciences). Beverly Hills, CA: Sage.

Beckstead, J.W. (2002). Using hierarchical cluster analysis in nursing research. Western Journal of Nursing Research, 24(3), 307-319.

Bennett, N., Wise, C., Woods, P.A., \& Harvey, J.A. (2003). Distributed Leadership. Nottingham: National College of School Leadership.

Bolden, R. (2011). Distributed leadership in organizations: A review of theory and research. International Journal of Management Reviews, 13, 251-269.

Bolden, R., Petrov, G., \& Gosling, J. (2008). Developing collective leadership in higher education: Final report. London: Leadership Foundation for Higher Education.

Bolden, R., Petrov, G., \& Gosling, J. (2009). Distributed leadership in higher education: Rhetoric and reality. Educational Management Administration \& Leadership, 37(2), 257-277.

Bryman, A., Stephens, M., \& Campo, C. (1996). The importance of context: Qualitative research and the study of leadership. Leadership Quarterly, 7(3), 353-370.

Burke, K.M. (2010). Distributed leadership and shared governance in post-secondary education. Management in Education, 24(2), 51-54.

Capra. M.G. (2005). Factor analysis of card sort data: An alternative to hierarchical cluster analysis. Proceedings of the Human Factors and Ergonomics Society 2005, 49, 691-695.

Everitt, B.S., Landau, S., Leese, M., \& Stahl, D. (2011). Cluster Analysis, $5^{\text {th }}$ ed. (Wiley Series in Probability and Statistics) West Sussex, UK: John Wiley \& Sons.

Freidrich, T.L., Bessey, W.B., Schuelke, M.J., Ruark, G.A. \& Mumford, M.D. (2009). A framework for understanding collective leadership. Leadership Quarterly, 20, 933-958.

Gronn, P. (2002). Distributed leadership as a unit of analysis. Leadership Quarterly, 13, 423-451. 
Guest, G., \& McLean, E. (2003). Distinguishing the trees from the forest: Applying cluster analysis to thematic qualitative data. Field Methods, 15(2), 186-201.

Harris, A. (2007). Distributed leadership: conceptual confusion and empirical reticence. International Journal in Education, 10(3), 315-325.

Harris, A. (2008). Distributed leadership: According to the evidence. Journal of Educational Administration, 46(2), 172-188.

Hughes, R. L., Ginnett, R. C., \& Curphy, G. J. (1993). Power, influence and influence tactics. In R. L. Hughes, R. C. Ginnett \& G. J. Curphy (Eds.), Leadership: Enhancing the lessons of experience. ( $2^{\text {nd }}$ ed.) Homewood, IL: Irwin.

Hulpia, H., Devos, G., \& Rosseel, Y. (2009). Development and validation of scores on the distributed leadership inventory. Educational \& Psychological Measurement, 69, 1013-1034

Hulpia, H., Devos, G., \& Van Keer, H. (2010). The influence of distributed leadership on teachers' organizational commitment: A multilevel approach. Journal of Educational Research, 103, 4052.

Jurowski, C., \& Reich A. Z. (2000). An explanation and illustration of cluster analysis for identifying hospitality market segments. Journal of Hospitality \& Tourism Research, 24(1), 67-91.

Leithwood, K., Day, C., Sammons, P., Harris, A., \& Hopkins, D. (2006). Successful school leadership: What it is and how it influences pupil learning. Nottingham: DfES Publications.

McBeath, J, Oduro, G.K.T., \& Waterhouse, J. (2004). Distributed leadership in action: A study of current practice in schools. Nottingham: National College for School Leadership.

Mayrowetz, D. (2008). Making sense of distributed leadership. Educational Administration Quarterly, 44(3), 424-435.

Osborn, R. N., \& Hunt, J. G. (2007). Leadership and the choice of order: Complexity and hierarchical perspectives near the edge of chaos. Leadership Quarterly, 18, 319-349.

Saenz, V. B., Hatch, D., Bukoski, B. E., Kim, S., Lee, K., \& Valdez, P. (2011). Community college student engagement patterns: A typology revealed through exploratory cluster analysis. Community College Review, 39(3), 235-267.

Spillane, J.P. (2006). Distributed Leadership. San Francisco: Jossey-Bass.

Spillane, J.P., Camburn, E.M., Pustejovsky, J., Pareja, A.S., \& Lewis, G. (2008). Taking a distributed perspective: Epistemological and methodological tradeoffs in operationalizing the leader-plus aspect. Journal of Educational Administration, 46(2), 189-213.

Uhl-Bien, M., \& Marion, R. (2009). Complexity leadership in bureaucratic forms of organizing: A meso model. Leadership Quarterly 20, 631-650.

Yukl, G. (2003). Influence Behavior Questionnaire (Agent G-44).

Yukl, G. (2004). Interactions in organizational change: Using influence tactics to initiate change. In: J. J. Boonstra, (Ed.) Dynamics of Organizational Change and Learning (pp. 301-315). New Jersey: John Wiley \& Sons.

Yukl, G., Seifert, C., \& Chevez, C. (2008). Validation of the extended influence behavior questionnaire. Leadership Quarterly, 19, 609-621.

Yukl, G. (2009). Leadership in Organizations, $6^{\text {th }}$ ed. Upper Saddle River, N.J.: Prentice-Hall.

Zirkle, L. (2012). Differentiating behaviors among Spillane's forms of distributed leadership.

(Unpublished dissertation). Gannon University, Erie, PA. 